\title{
Enfermedad y dolencia
}

\author{
Disease and aching.
}

Dr. Enrique Galli

Jefe del Departamento de Psiquiatría

Universidad Peruana Cayetano Heredia

A 25 años de la desaparición del Profesor Dr. Honorio Delgado, es pertinente hacer recordar a los estudiantes y profesores universitario la conceptualización de "Humanización de la Medicina" por él elaborada.

Recordaremos lo que dice Honorio Delgado acerca de la enfermedad y la dolencia.

1. "No hay enfermedades sino enfermos".

2. “Saber que enfermedad tiene una persona, es más importante, que saber que persona tiene una enfermedad?".

3. Cuando nosotros curamos enfermedades, ¿nos preocupamos de la dolencia?.

"La gradación que existe entre la salud y la enfermedad ofrece problemas de gran momento en lo tocante al aspecto subjetivo. En efecto, cabe distinguir la enfermedad sufrida de la enfermedad ignorada o inaparente: La primera se manifiesta al individuo en cuyo cuerpo se produce; la segunda es un proceso que daña al organismo, a veces con lesiones considerables y que conducen a la muerte, sin que el sujeto se percate durante un tiempo de su existencia. De suerte que el sufrimiento anexo al desorden patológico no es legítimo considerarlo como condición sine qua non de la enfermedad. Este es uno de los hechos que justifica nuestra distinción entre enfermedad y dolencia".

"La dolencia entraña ante todo, el conocimiento o la idea de estar enfermo, noción fundada o puramente aprensiva. Tal noción surge de la impresión de saberse o creerse enfermo, impresión que en el caso corriente depende de la percepción efectiva y directa del desorden patológico por la cenestesia, especialmente por las sensaciones viscerales. La enfermedad, en efecto, se acompaña en la mayor parte de los casos de sensaciones más o menos difusas o localizadas, mayormente acompañadas de estados afectivos vitales y sensoriales.

“Al fenómeno del simple y espontáneo advertir de la existencia en el organismo de perturbaciones morbosas sigue o acompaña la atención prestada $\mathrm{y}$, consiguientemente, la auto observación empeñada en esclarecer la naturaleza del mal que se sufre y la amenaza de sus consecuencias; auto observación cuya intensidad depende del temperamento del sujeto, máxima en individuos impresionables y sobre todo en los de personalidad asténica o con rasgos asténicos. El interés del enfermo, acicateado por la auto observación despierta y excita su fantasía, no sólo acerca de lo que es actualmente la perturbación de su organismo, 
sino de lo que puede ser, llevándolo acaso a sobrevalorar hasta las últimas consecuencias. Pues una enfermedad, que no sea trivial, constituye para quien la sufre si no un momento moris, por lo menos motivo de preocupaciones pronósticas, más o menos intraquilizadoras.

Después de lo expuesto, creo que tan importante es saber que enfermedad tiene una persona como también que persona tiene una enfermedad. Hay que tener presente que hay enfermedades sin dolencia y también dolencias sin enfermedades. Hay que tener presente que hay enfermedades sin dolencia y también dolencias sin enfermedades que son las que sufren un buen porcentaje de pacientes que se ven en la práctica médica. También hay que tener presente que curar no es sanar. Se sana solamente cuando se actúa sobre la dolencia, por eso quien cura no necesariamente sana.

\section{CONOCIENDO AL INDIVIDUO ENFERMO}

Cada individuo es un ente cerrado e impenetrable a otros individuos, dentro del cual no se conoce lo suficiente. Scheler dice: "Si quieres comprender a los demás, mira tu propio corazón; si quieres comprenderte a ti mismo, mira como se conducen otros".

Pero Delgado agrega: "Ni por el común denominador psíquico, ni por la común participación espiritual se llega a conocer al ser ajeno". El Maestro habla de la "Intuición interindividual". Mariátegui de la "Comunicación intersubjetiva", que no es sino la perspicacia del entrevistador, como una secreta adivinación, producto de la experimentada elaboración de información, imparcialidad y eficacia que nos lleva lo más cercano posible al crecimiento del individuo. Sin embargo coincidimos con Delgado que la esencia de lo peculiar, incluyendo a nuestros seres más cercanos, es inescrutable.

La entrevista es, sin lugar a dudas, el elemento fundamental para el conocer del ser ajeno, esa "observación participante" (Sullivan), "ese amor psicoterapéutico" (Seguín), "ese eros es la comunicación perspicaz e intersubjetiva" (Galli).

Lo fundamental de la entrevista es alcanzar, lo más que se pueda, la vivencia actual en la manifestación expresiva del paciente. El profesor Delgado advierte que: "El investigador de almas reflexivo se cuida de no violentar con sus métodos o con ideas preconcebidas la filigrana de la vida, cuyas manifestaciones concretas aquilata".

\section{LO PSICOSOMATICO}

Los tres eminentes pensadores del siglo XVII, Descartes, Spinoza y Leinbniz, se ocuparon del problema de la relación Mente y Cuerpo, Heinroth (1808) crea el término "Psicosomático". Jacob (1822) crea el término "Somatopsíquico". Jasper (1913-1950) identifica "lo psíquico como espiritual" y lo denomina alma. Delgado (1950-1968) separa lo psíquico, lo biológico y lo espiritual.

Cobb (1950) postula que lo psíquico debe ser considerado en todas las ramas de la medicina. Ahora hacia el ocaso del siglo XX, la medicina integral es su presente y su futuro desde un enfoque: "Biopsicosocial", pero nosotros postulamos que debiera ser: "Biosociopsicoespiritual" (Galli). 
La primera mitad de este siglo ha sido el dominio de lo Psicológico (Freíd) y la segunda mitad de lo biológico (Psicofármacos).

Esperamos que en base a Delgado y Cobb, el Siglo XXI sea de afronte biopsicoespiritual.

Al fín: La enfermedad y la dolencia dentro del contexto de la entrevista deja una huella en lo psicosomático y en lo espiritual. El énfasis en estos 3 conceptos: enfermedad - dolencia, entrevista y lo biopsicoespiritual es la reivindicación en la humanización de la medicina. 